\title{
i-TRASHER- SMART WASTE MANAGEMENT SYSTEM
}

\section{RAGHUNANDAN. G H ${ }^{1}$, KEERTHI KUMAR. $\mathbf{N}^{2}$, KARUNYA SANKAR ${ }^{3}$ \& RUSHANK PRABHUDESAI \\ ${ }^{1,3,4}$ Department of Electronics and Telecommunication Engineering, BMS Institute of Technology and Management,} Bengaluru, India

${ }^{2}$ Department of Mechanical Engineering, BMS Institute of Technology and Management, Bengaluru, India

\begin{abstract}
All day to day activities required to manage waste from the time to time. It should be safely disposed is collectively called waste management. Waste management is a crisis growing in terms with environmental pollution which is a major public health issue. Waste management System will serve as a solution for this rising issue. This system plays a very vital role in the development of smart waste management system. Most of the waste collected is not treated and as a result harmfulgases are released. This proposed system in this paper serves the purpose to convert these waste materials into useful product. The waste is treated from the time of its inception making it friendlier to the environment. It reduces the spread of infections and bugs which may contaminate the environment when waste is left open. The proposed system i-Trasher is faster and eco-friendly in converting waste to compost. The compost generated can be used in gardens, agriculture and farming. The compost has many benefits for the soil making it a conditioner, a fertiliser and a natural pesticide for the soil. The main aim of $i$-Trasher is to produce pure and utilisable compost in an efficient manner and faster rate. Our proposed system not only deals with the organic waste, it also deals with the plastic waste which is non-biodegradable. The proposed system demonstrates its capability of effectiveness and rapid processing, and also its smartness.

KEYWORDS: Waste Management, Compost, Smart recycling, Organic, Plastic
\end{abstract}

Received: Jun 09, 2020; Accepted: Jun 29, 2020; Published: Aug 11, 2020; Paper Id.: IJMPERDJUN2020721

\section{INTRODUCTION}

The disposal of garbage, sewage, and other waste products, transportation and collection of it in simple terms is known as waste management. Treating of solid and liquid waste is also a part of this process. There are multiple solutions for recyclable items which cannot be categorised as trash. The whole idea of waste management is narrowed down to reusing the waste products as valuable resources. This could be useful for household as well as business purposes. There are many advantages that come with the treating and management of waste in correct manner. The biggest advantage is that a better, clean and disease free atmosphere is created to live in. This can only be experienced when the disposal and treatment of the waste is done in the right manner. Reduction is pollution is the second advantage. Impact from Harmful gases such as carbon di oxide, methane, carbon monoxide can be reduced by managing waste in the right way which does not eliminate the unwanted products. Speaking about its role in the conservation of energy, this can be seen the process of recycling paper. Recycling paper helps in the reduction of cutting down trees while it also helps in the reduction of carbon footprints. It helps in the development and generation of employment for people in a large scale. This in turn leads to more people adapting eco-friendly practices. The two major factors that contribute to waste generation are growth in population and industrialisation which has created a major concern of waste disposal for several decades. Though there is some advancement being made in waste disposal methods they aren't adequate enough. Looking as some of the methods we have: 


\section{Reduction \& Preventive Measures of Waste Generation}

The main cause of waste formation know so far is the extensive use of unnecessary products and constant buying of new products. The rapid growth in population has also added excessive generation of waste. To control the growth of waste judiciously a conscious decision has to be taken to use all the existing products efficiently at personal and professional level.

\section{Recycling}

Recycling means changing or transforming wastes into new products of similar kind by processing it industrially. Some of the recyclable products are glass, paper, aluminium and plastics. The reuse of wastes rather than disposal is environmentally friendly but also economical.

\section{Incineration}

The process of transforming waste products to their base components by combustion is known as incineration. Energy is derived by trapping the generated heat. Some of the by-products of incineration are assorted gases and inert ash. Varied degrees of pollution are caused depending on how the incinerator is designed and nature of the combusted waste. This method can be used for getting rid of hazardous and toxic wastes.

\section{Composting}

The process of decomposing of organic waste using microbes by keeping it accumulated in a lit for a very long time is known as composting. This compost is rich in nutrients and can be used as fertilisers for plants. This is a very slow process and a significant area of land is also consumed. The fertility of the soil can be improved by reprocessing it biologically.

\section{Sanitary Landfill}

The dumping of waste in a landfill is what is done in this method. To avoid contamination of the ground water by chemical substances a protective lining is lauded in between the waste and the ground water which acts as a barrier. This protective lining is also known as the base. To reduce odour from the waste the waste layers are coated with sand. The vulnerability of toxic chemical being leaked accidentally is avoided by the soil. Places with low ground water level and far from sources which can cause floods are suitable for a landfill.

\section{Disponal in Ocean/Sea}

Generally this method is used only for radioactive active elements. The waste is generally dumped in faraway oceans very far from human habitats. This could be a threat to aquatic habitats which is the reason why it is being challenged by environmentalists.

\section{Plasma Gasification}

The method of waste disposal to recycle municipal solid waste in landfills to sources of energy is known as plasma gasification. Syngas is prepared by converting the carbon-based materials, exposing them to high temperatures. Though there are several methods to dispose wastes as a mass quantity, the control in the pollution and littering can only be got by the small scale and early disposal stages. This is nothing but the disposal at every house in an individual level. The mass disposal methods mentioned above are done only after the wastes from houses are picked up. If processing of the disposed wastes is done at the early stage itself, there will be reduction in the chaos a pollution caused. Making use of the products 
obtained by this processing can also cut the cost of buying new products and can also be used for profit. According to recent statistical reports, Organic, paper and plastic wastes are the most disposed and hence i-Trasher specifically on the major part of the disposed waste. According to the statistics, $43 \%$ of the wastes disposed comes under the category of organic wastes, $26 \%$ under paper and $13 \%$ under paper.

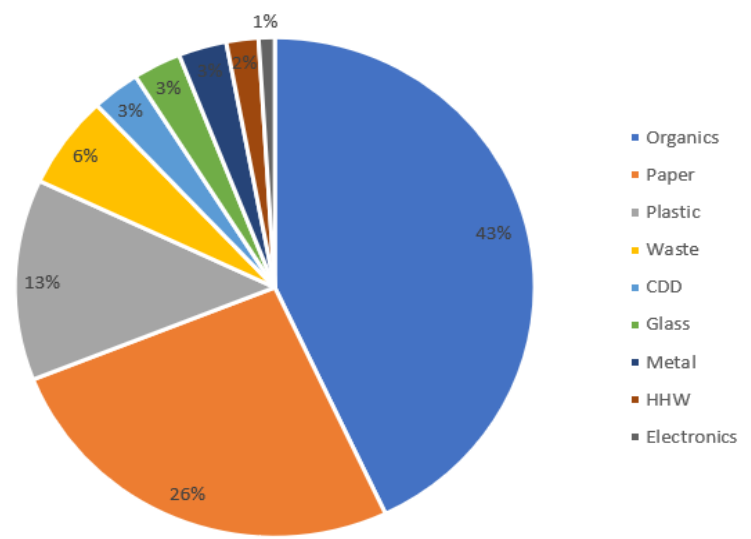

Figure 1: Types of Wastes Disposed.

Another statistical report (Fig.2) shows that $44 \%$ of wastes produced are food and green which are again under the category of organic wastes $17 \%$ paper and cardboard wastes and $12 \%$ plastic wastes. Through both the reports it can be concluded that i-Trashes focus on the major parts of the wastes produced.

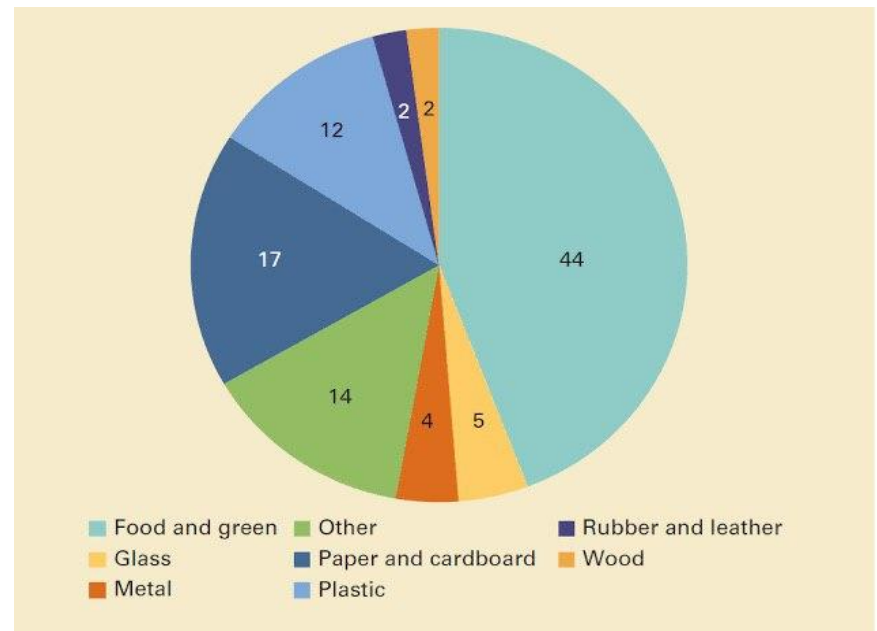

Figure 2: Category of Wastes Disposed.

Next set of report speaks about the origin of wastes (shown in Fig.3). Majority of the wastes, i.e. about $43 \%$ of the wastes is domestic household wastes, $15 \%$ is from the hotels and restaurants. The target audience of i-Trasher is the same set of categories along commercial establishments which is $8 \%$ of the production source. 


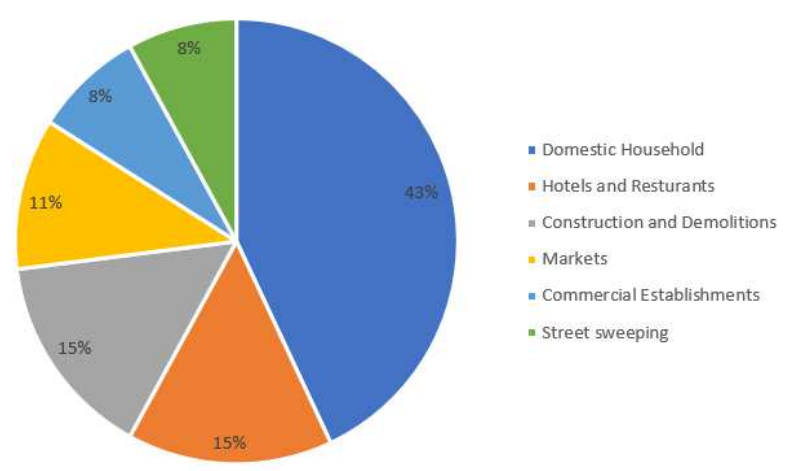

Figure 3: Source of Disposed Waste.

The next section will speak about the various existing waste management systems along with their specific roles in bring out development in the field of waste management. Every system has its own contribution to bring improvements in the existing systems.

\section{EXISTING SYSTEMS}

System [1] states that the main focus of this system is on the concept of connection of all bins to a common network to control and overview the trash bins present in the city making it helpful. The main aim of this system is to avoid overflow of waste and to help the workers in cleaning the bins. The idea of automation is being implemented for waste management all over the city using the i-bins. Technologies such as raspberry pi, IR/ultrasonic sensors and weight sensors have been used. The system only focuses on the overflow which is only one part of the growing crises. In [2] spilling out of waste from bins by over flooding brings about contamination to the public places. Infections are increased due to the breeding of huge amounts of bugs on them. The main aim of this system is to monitor the level of waste and disposal of waste automatically. This task of the system comes into action only after the disposal of wastes in the correct manner. In [3] it is stated that the main aim of this system is to detect the overflow of waste using wireless networks (WSN) and IoT. Sensors are deployed in the bins and WSN is used for networking them together. Data for every determined interval is collected using the sensors which are deployed. A request is raised to the garbage collector agent once the threshold is reached. All the filled vehicles are collected by the agent once requested using IoT framework. The functioning of this system is similar to the [2] but with a different technological approach. With [4] the research and development of a home composter specially designed for household is shown in this system. The organic kitchen and food waste can be utilised, disposed and managed at the source of waste generation. Easy usage and easy user interface have been ensured. The output compost is ready to use for the application of plants. Hence the kitchen waste bin is effectively replaced by the home composter. The system [5] introducing a practical solution to recycle the food waste instead of throwing them into the landfill. An ecofriendly machine is designed to convert food waste into fertilizer. The process is completely automated, it works under certain environmental conditions (i.e. temperature, humidity) to fasten the process. This can be a drawback as the environmental conditions vary a lot. In system [6], aims to convert waste to compost using the composting process. Temperature and humidity are maintained to certain levels in order to start the process. They aim to decrease the wastes dumped in landfills and to provide better quality of compost. Using the self-heating method for compost can be time consuming which can delay the composting process. In [7] have come up with a SMART Composting Machine. The machines can 10 to $15 \mathrm{~kg}$ of organic waste into usable compost. But it is not efficient system. 


\section{PROPOSED SYSTEM}

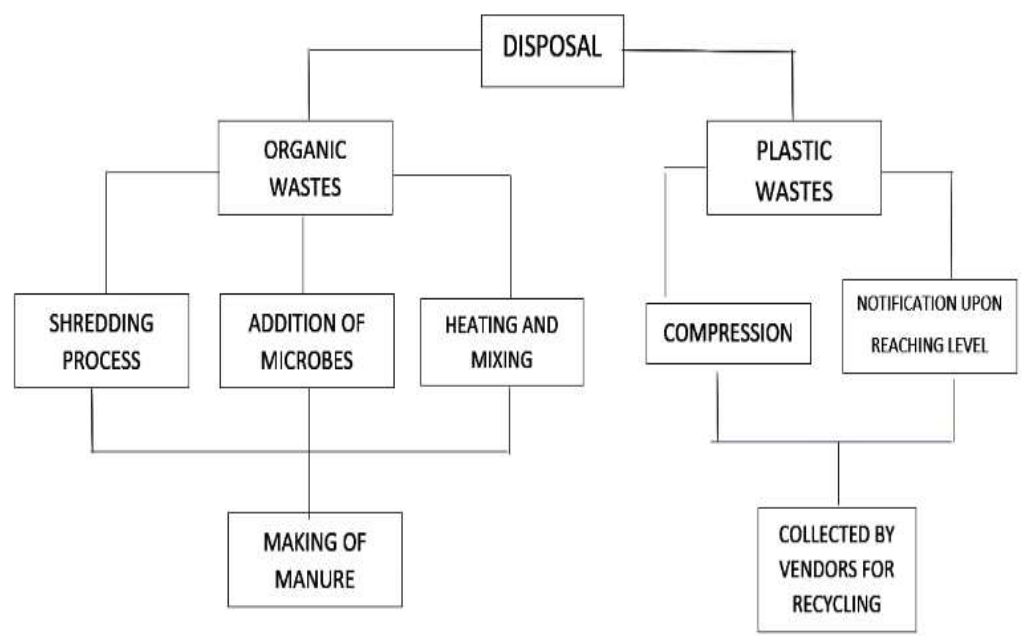

Figure 4: Working of System.

The waste is first collected in two separate compartments, one for plastic and the other for organic waste. This organic waste is passed through a shredder and is shredded to fine pieces. This waste is simultaneously mixed with the microorganisms while being shredded. The mixture is then heated up to a certain temperature and constantly stirred. It takes 20-24 hours for the waste to get converted into compost. The compost is then drained out of its excess water and then collected in a tray which is removed out of the machine after this process ends. The plastic waste collected in the first compartment is compressed with the help of a piston which can be removed as the compressed plastic reaches a certain level which in turn would send a notification to the nearby plastic dealers to collect the plastic. These two processes in both the compartments take place simultaneously making this machine very efficient and smarter than the existing technologies.

\section{IMPLEMENTATION}

The design of i-Trasher consists of two compartments, the compartment at the top is for the plastic wastes and the compartment at the bottom is for organic wastes. There are two outputs on each side to collect the respective wastes after processing (shown in Fig.5).

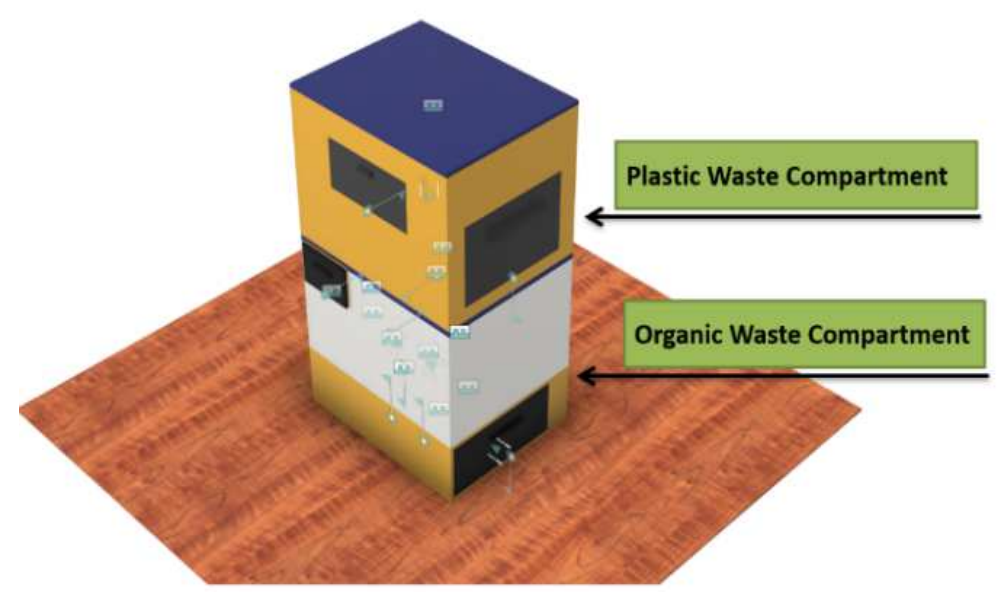

Figure 5: Outer Design with Compartments. 
The plastic waste compartment is fixed with a piston for compression. The piston is attached with protruding needle-like structures which will help in removing the air from the plastic wastes.
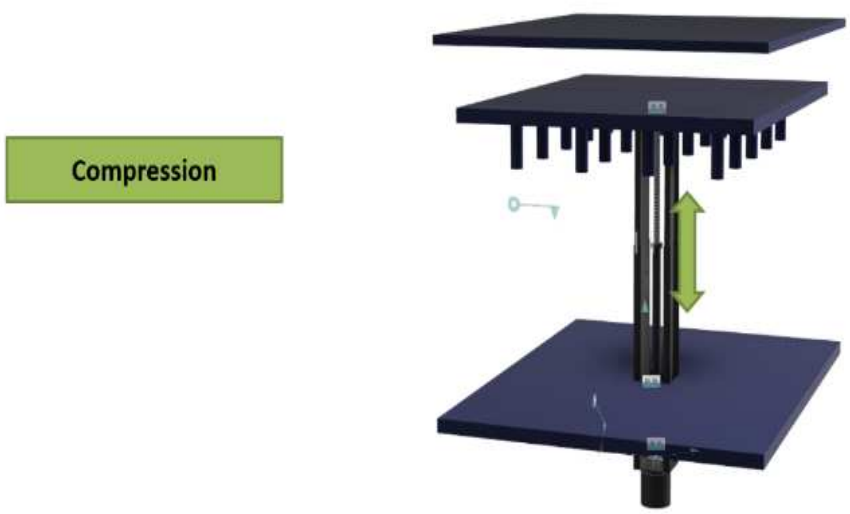

Figure 6: Plastic Waste Compression.

Once the waste are compressed and reaches a certain level, a notification will be sent for the plastic wastes to be collected.

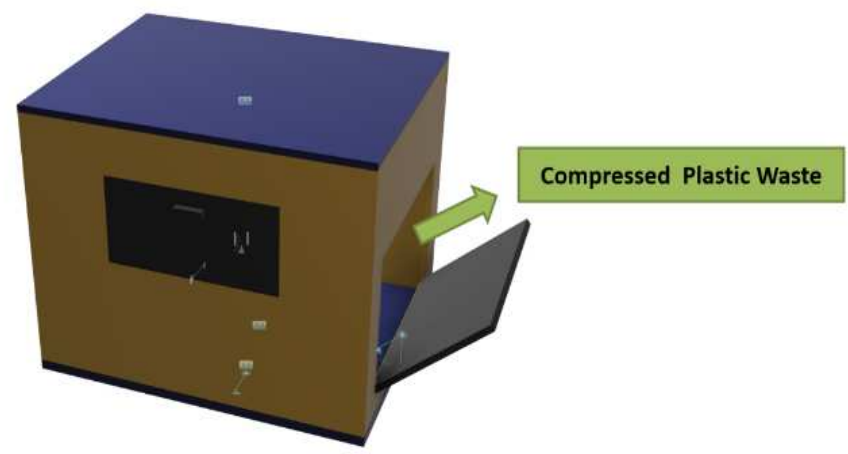

Figure 7: Plastic Waste Outlet.

The organic compartment is provided with an input and output port. A shredder has been installed to cut down the wastes into tiny particles which speeds up the process of conversion. We have a heater as well as microbes which help in the compost making process.

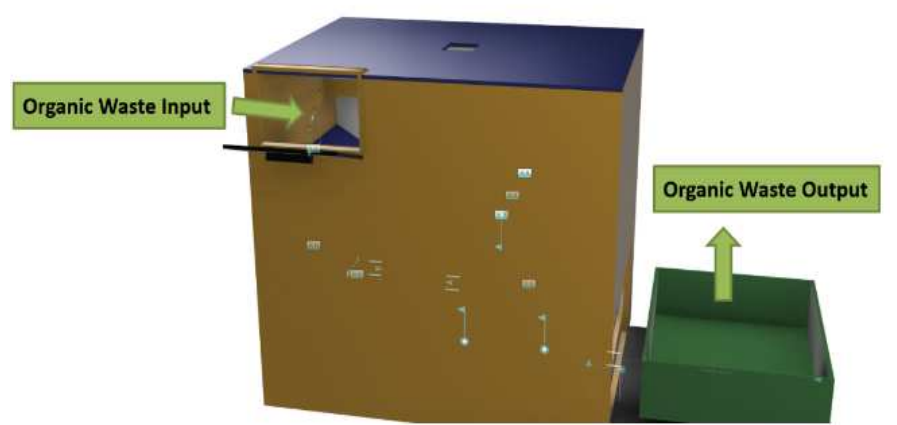

Figure 8: Organic Waste Compartment. 
Once the compost is ready, they are transferred into the tray which can be opened as an outlet in order to access the converted compost.

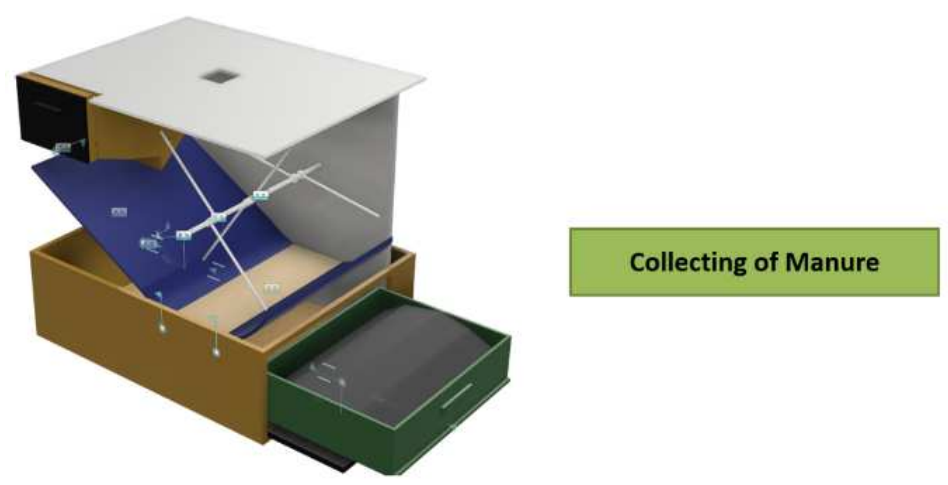

Figure 9: Organic Waste Process and Outlet.

\section{RESULTS AND EVALUATION}

Waste management is very crucial in the present days. Recycling the materials is as important as disposing them in the correct manner. i-Trasher focuses on the majority part of the waste disposed and it efficiently converts them into useful products. Most importantly, the process starts at the beginning stage of disposal. It works on two categories of wastes simultaneously without any disturbances to their specific processes. It helps in segregation as well as converting them into a useful set of products which can in turn be a source of profit for the user. i-Trasher is a product that made using smart technologies which makes it unique and easy to operate. It includes segregation, level detection, smart way to notify vendors as well as converting wastes to useful products. The targeted users are the main source of waste disposal. The system is made smart enough by equipping with IoT techniques. The network layer is responsible for transferring the measured information in the perception layer to the upper layers, where the processing systems are located, and uses ZigBee, Z-wire, GSM, UMTS, Wi-Fi, Infrared, 6LoWPAN. In addition to the basic assignments, the network layer also performs the cloud computing process and the data management process. The load sensor is coupled to a specific driver, such as HX711, which amplifies the signal emitted by the load cell in addition to providing interconnection with the microcontroller. The microcontroller based IoT system is used which automatically sends the message to the waste collector along with exact weight of the waste material and location. So this system will manages the waste systematically and waste descipation is also made easy. The farmers will be getting the compost and waste material collectors will be getting it in systematic way. The customer who is using this system will be paid by the farmers and waste material collectors based on the weight of compost and waste materials they receive. 


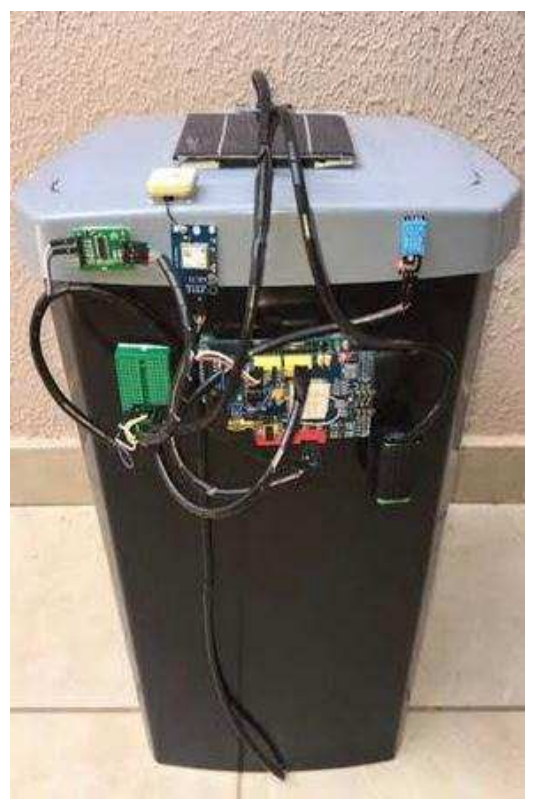

Figure 10: Prototype of System.

\section{CONCLUSIONS}

i-Trasher converts the wastes into useful products. This is beneficial to the user because when the waste is recycled, they would not have to be reused to make the same products. The environmental benefits that come from recycling is that less waste which is thrown. This won't cause any harm to the people living in the area. i-Trasher can also help in making money or a source of profit. A waste collection business can also be started is a large amount of waste is being dumped. There will be people who will pay someone for getting their waste collected. The recycled products can be sold to manufacturers or vendors which could be another were of earning or making money. You can also use the converted compost as organic fertilizer. We can sell our compost to companies who make them in large numbers. It can also be used for feeding the soil with nutrients in the farm. i-Trasher starts the processing at early stages. This is an advantage because of the garbage is left for long it starts emitting harmful toxic gases by mixing up with other unwanted waste components. This means that pollution could be caused by the toxic material if the trash is not handled properly in the initial stages and will be harmful to humans and other living things. It will become a public hazard and can cause environmental destruction.

\section{REFERENCES}

1. Krithika. S, Kaja Maideen J, Madan T K C,"An Automated Trash Monitoring System for Waste Management Using IoT- (IBin)", International Journal of Engineering and Advanced Technology (IJEAT), Volume-8, Issue-63, September 2019

2. S.Sreejith, R.Ramya, R.Roja, A.Sanjay Kumar, 2019 Smart Bin for Waste Management System, 2019 5th International Conference on Advanced Computing \& Communication Systems (ICACCS),May 2019

3. Sivasankari, Bhanu Shri and Y.Bevish Jinila, "Smart Waste Management Using WSN and IoT", 2017 International Conference on Innovations in Information, Embedded and Communication Systems (ICIIECS 2017), March 2017.

4. Farooqi, Awais. "A Green Strategy towards the Miscibility Studies of Styrofoam in Organic and Inorganic Solvents by Using Materials Modelling and Simulation Method." Journal of General Engineering and Technology (JGET) 1 (2016): 11-18.

5. Nithika Sailesh, Vikas Shinde, Home composter: Domestic use composter,2015 World Congress on Sustainable Technologies (WCST) May 2015. 
6. Gaurav Chiplunkar and Prof. (Dr.) Avinash More, Design of Kitchen Waste Composting Machine. International Journal of Trend in Research and Development, Volume 5(3),May - Jun 2018.

7. Asif, Muhammad Salman. "An Appraisal of Issues Faced by Manufacturing Companies, When Selecting an Enterprise Resource Planning (ERP) System." International Journal of Business and General Management (2018): 1-8.

8. Shada Bennbaia, Aseel Wazwaz, Alaa Abujarbou. Towards Sustainable Society: Design of Food Waste Recycling Machine Proceedings of the International Conference on Industrial Engineering and Operations Management Bandung, Indonesia, March 6-8, 2018

9. Swapnesh H. Bhaisare, Dr.Pramod Walke, Dr. D. S. S. Ganguly, V.M. Wankar. The Organic Compost Machine and Factors Effecting Performance of composting. International Journal of Engineering Science and Computing, December 2017.

10. Nurdin, Ismail. "Analysis and Utilization of Space as a City Area through Government Policy: Study in Solok District, Indonesia." International Journal of Humanities and Social Sciences (IJHSS) 8.5 (2019): 7-16.

11. Mohammed Adnan, Mohammed Elnour, Omer Mohammed Tawfeeq, Mohammed Awad. Waste Management System Using IoT. International Conference on Computer, Control, Electrical, and Electronics Engineering (ICCCEEE). IEEE. June 2018

12. Ravi Kishore Kodali, Venkata Sundeep Kumar Gorantla. Smart solid waste management. 3rd International Conference on Applied and Theoretical Computing and Communication Technology (iCATccT). IEEE. July 2017

13. Gopal Krishna Shyam, Sunilkumar S Manvi, Priyanka Bharti. Smart waste management using Internet-of-Things (IoT). 2nd International Conference on Computing and Communications Technologies (ICCCT). IEEE. March 2017

14. Amusan, L. M., et al. "Information on State of Challenges of Waste Management System in Nigeria Urban Housing System." International Journal of Mechanical and Production Engineering Research and Development 8.2 (2018): 75-86.

15. K N Fallavi, V Ravi Kumar, B M Chaithra. Smart waste management using Internet of Things: A survey. International Conference on I-SMAC (IoT in Social, Mobile, Analytics and Cloud) (I-SMAC). IEEE. June 2017.

16. Priyanka Shrivastava, Shivangi Mishra, S.K.Katiyar. A Review of Solid Waste Management Techniques Using GIS and Other Technologies. International Conference on Computational Intelligence and Communication Networks (CICN). IEEE. May 2015

17. Shubham Thakker, R Narayanamoorthi. Smart and wireless waste management. International Conference on Innovations in Information, Embedded and Communication Systems (ICIIECS). IEEE. October 2015

18. Fachmin Folianto, Yong Sheng Low, Wai Leong Yeow. Smartbin: Smart waste management system. IEEE Tenth International Conference on Intelligent Sensors, Sensor Networks and Information Processing (ISSNIP). IEEE. June 2015 

